\title{
PEDIATRIC ORIGINAL ARTICLE \\ Patterns of childhood body mass index (BMI), overweight and obesity in South Asian and black participants in the English National child measurement programme: effect of applying BMI adjustments standardising for ethnic differences in BMI-body fatness associations
}

\author{
MT Hudda ${ }^{1}$, CM Nightingale ${ }^{1}$, AS Donin ${ }^{1}$, CG Owen ${ }^{1}$, AR Rudnicka ${ }^{1}$, JCK Wells ${ }^{2}$, H Rutter ${ }^{3}$, DG Cook ${ }^{1}$ and PH Whincup ${ }^{1}$
}

BACKGROUND: The National Child Measurement Programme (NCMP) records weight and height and assesses overweight-obesity patterns in English children using body mass index (BMI), which tends to underestimate body fatness in South Asian children and overestimate body fatness in Black children of presumed African ethnicity. Using BMI adjustments to ensure that adjusted BMI was similarly related to body fatness in South Asian, Black and White children, we reassessed population overweight and obesity patterns in these ethnic groups in NCMP.

METHODS: Analyses were based on 2012-2013 NCMP data in 582899 children aged 4-5 years and 485362 children aged 10-11 years. Standard centile-based approaches defined weight status in each age group before and after applying BMI adjustments for English South Asian and Black children derived from previous studies using the deuterium dilution method.

FINDINGS: Among White children, overweight-obesity prevalences (boys, girls) were $23 \%$ and $21 \%$, respectively, in $4-5$ year olds and $33 \%$ and $30 \%$, respectively, in 10-11 year olds. Before adjustment, South Asian children had lower overweight-obesity prevalences at 4-5 years (19\%, 19\%) and slightly higher prevalences at 10-11 years (42\%, 34\%), whereas Black children had higher overweight-obesity prevalences both at $4-5$ years $(31 \%, 29 \%)$ and $10-11$ years $(42 \%, 45 \%)$. Following adjustment, overweightobesity prevalences were markedly higher in South Asian children both at 4-5 years (39\%, 35\%) and at 10-11 years (52\%, 44\%), whereas Black children had lower prevalences at 4-5 years (11\%, 12\%); at 10-11 years, prevalences were slightly lower in boys (32\%) but higher in girls (35\%).

INTERPRETATION: BMI adjustments revealed extremely high overweight-obesity prevalences among South Asian children in England, which were not apparent in unadjusted data. In contrast, after adjustment, Black children had lower overweight-obesity prevalences except among older girls.

FUNDING: British Heart Foundation, NIHR CLAHRC (South London), NIHR CLAHRC (North Thames).

International Journal of Obesity (2018) 42, 662-670; doi:10.1038/ijo.2017.272

\section{INTRODUCTION}

Childhood obesity is a major public health problem both globally ${ }^{1}$ and in England, where approximately one-third of children aged 2-15 years were recently reported to be overweight or obese using body mass index (BMI). ${ }^{2}$ Childhood overweight-obesity is associated with adult overweight-obesity, ${ }^{3}$ and with higher risks of type 2 diabetes and cardiovascular disease. ${ }^{4-6}$ Overweight-obesity in English South Asian and Black children of African origin is of particular concern; both ethnic groups have high type 2 diabetes and cardiovascular disease risks in adulthood, ${ }^{7-10}$ originating in childhood. ${ }^{11,12}$

Accurate assessment of overweight-obesity prevalence in English South Asian and Black children is therefore important. Most national surveys, including the National Child Measurement Programme (NCMP) and the Health Survey for England, ${ }^{2,13}$ use
BMI to categorise overweight and obesity identically in all ethnic groups. However, the relations between BMI and body fatness differ by ethnicity both in adults and children. Asian adults tend to have a lower BMI for a given body fatness than Whites. $^{14}$ Among English children, more specifically, BMI systematically underestimates body fatness in South Asians and overestimates it in Blacks. ${ }^{15,16}$ We recently developed ethnicspecific BMI adjustments, which provide adjusted BMI values for South Asian and Black children, which have the same relation to body fatness as in White children. ${ }^{17}$ In this report, we have applied these BMI adjustments to recent NCMP data to obtain an improved picture of the burdens of body fatness, as reflected in adjusted overweight-obesity prevalences in South Asian and Black children and in the English child population as a whole.

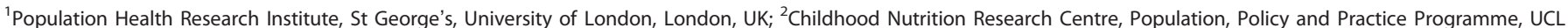

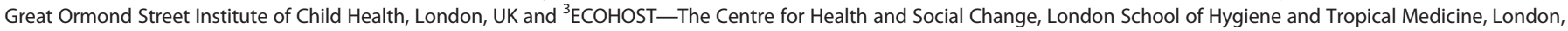
UK. Correspondence: Mr MT Hudda, Population Health Research Institute, St George's, University of London, Cranmer Terrace, London SW17 ORE, USA. 


\section{METHODS}

National Child Measurement Programme (NCMP)

Participants. The NCMP is an annual survey of the weights and heights of English children aged $4-5$ years (reception year) and 10-11 years (Year 6) carried out since 2006-2007, currently directed by Public Health England; data collection is conducted by Local Authority (LA) public health departments. ${ }^{18}$ All state primary schools in England $(n \sim 17000)$ are invited to participate; within participating schools, all relevant pupils are invited to participate on an opt-out basis. This report is based on the 2012/13 survey, the most recent for which relevant information including pupil ethnicity was available from the HSCIC (Health and Social Care Information Centre), now NHS Digital. Overall, $93 \%$ of eligible children participated. ${ }^{13}$

Data collection. Weight and height were measured by assessment teams recruited, trained and supervised by LA public health departments. Public Health England provided detailed instructions on instrument choice and calibration (requiring the use of annually checked Class III weight scales) and measurements, made without shoes in light indoor clothing. Weight was measured to the nearest $0.1 \mathrm{~kg}$ and height with the child's heels together and the head in the Frankfurt plane to the nearest $0.1 \mathrm{~cm}$. BMI was calculated as weight per height ${ }^{2}$. School record information on name, date of birth, sex and parentally defined ethnicity was collected. Data were entered using the NCMP IT system and collated by HSCIC.

NCMP BMI category definitions. The NCMP uses the British 1990 child growth reference population (UK90) to assign each child a BMI centile taking into account their height, weight, sex and age. ${ }^{18,19}$ Children are classified using population level thresholds as underweight (2nd centile or below), healthy weight (above 2 nd centile, below 85 th centile), overweight (on or above the 85th centile and below the 95th centile), or obese (on or above the 95th centile). 'Overweight-obesity' combines children who are overweight or obese (on or above the 85th centile). These population level thresholds follow standard NCMP reporting practice. ${ }^{18}$ More extreme clinical BMI centile thresholds identify children who are overweight (on or above the 91st centile, up to the 98th centile) or obese (on or above the 98th centile) as a basis for informing parents of their child's weight status. ${ }^{18}$ Clinical 'overweight-obesity' refers to children on or above the 91st BMI centile.

Ethnicity. Ethnicity was defined using the National Health Service classification. ${ }^{20}$ For the present analyses, children identified as 'White British', 'White Irish' and 'any other White background' were grouped as 'White'. Children identified as 'Black African', 'Black Caribbean' or 'any other Black background' were of presumed African origin and grouped together as 'Black'. Children of 'Indian', 'Pakistani' or 'Bangladeshi' origin were grouped as 'South Asian'. Children of 'Chinese' or 'Asian other' origins were grouped as 'Other Asian'. Children of 'any other ethnic background' and 'mixed ethnicity' were grouped as 'Other ethnicity'. Children with missing ethnicity data formed a separate category of 'Unknown'.

Adjusted BMI values for black and South Asian children. Ethnic-specific BMI adjustments for Black and South Asian children were derived using pooled data from four recent studies that used the deuterium dilution reference method to assess fat-free mass (and indirectly fat mass) in Black, South Asian and White children aged $4-12$ years. ${ }^{17}$ BMI adjustments were derived using sex-stratified regression models, which ensured that adjusted BMI values were associated with fat mass (based on the reference method and expressed as a height independent fat mass index (fat mass per height $\left.\mathrm{t}^{5}\right)$ in the same way as in Whites. ${ }^{17}$ Regression models were adjusted for ethnic group and age group (in 3-year age groups (4.0-6.9, $7.0-9.9$ and $10.0-12.9$ years)) to provide robust and stable estimates. Model building was conducted using a stepwise forwards approach; two-way

Table 1. Characteristics of participants in the national child measurement programme (2012-13): by age-sex group

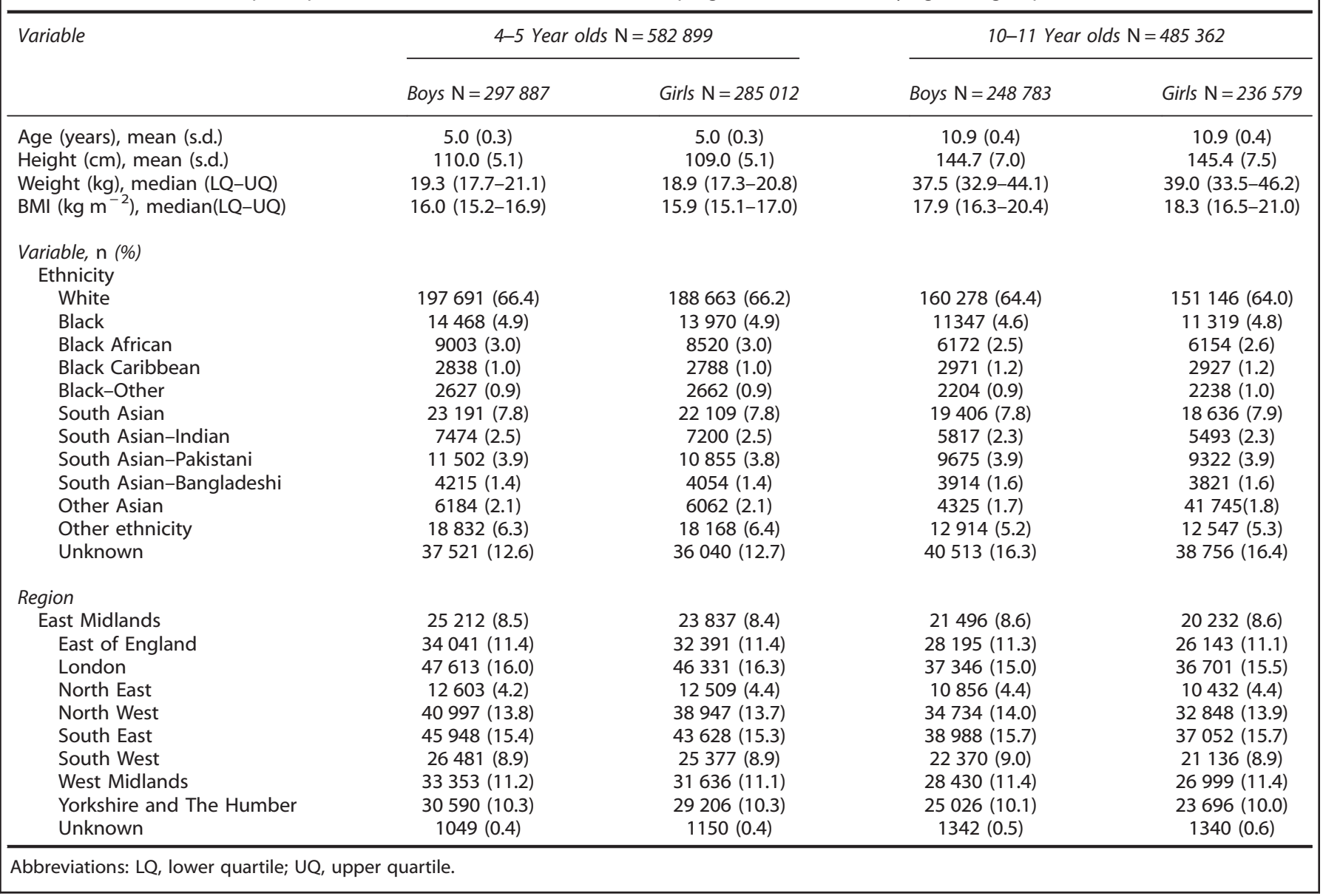



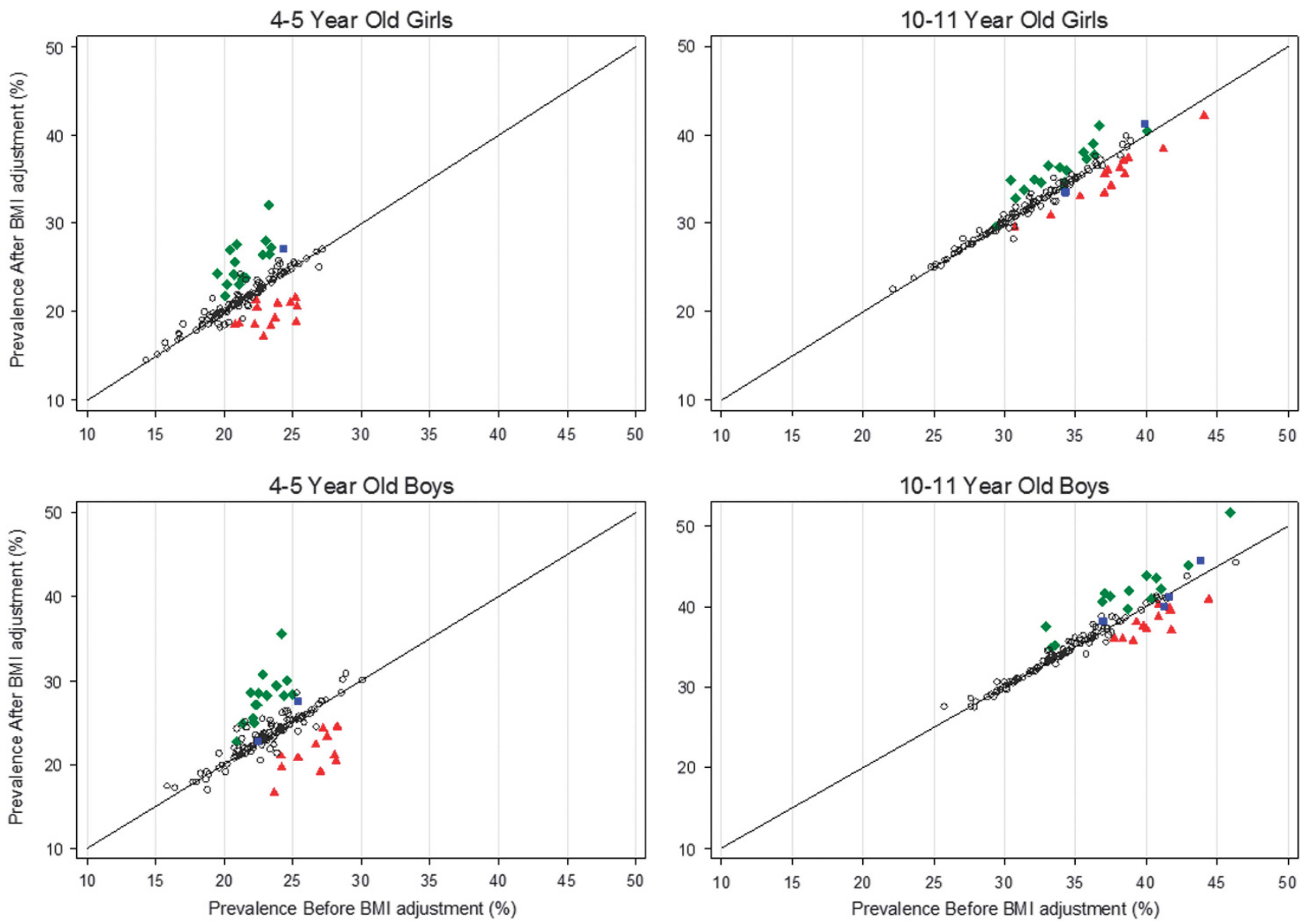

Figure 1. Correlation of prevalences of overweight-obesity in local authorities before and after BMI adjustments by age-sex group in the national child measurement programme (2012-13). Local authorities are colour coded by ethnic composition. Legend: open circles $=$ South Asian \& Blacks $<20 \%$, green diamond=South Asian $\geqslant 20 \%$ \& Blacks $<20 \%$, red triangle $=$ Blacks $\geqslant 20 \%$ \& South Asian $<20 \%$, blue square $=$ South Asian \& Blacks $\geqslant 20 \%$ Based on the overweight-obesity population thresholds: overweight-obese: $\geqslant 85$ th centile Excluding areas with potential data quality issues and areas with $<1000$ individuals.

interaction terms between $\mathrm{FMl}$, ethnic group and age group were included in the model and three way interactions were only considered if their corresponding two-way interactions were statistically significant at the $5 \%$ significance level. ${ }^{17}$ For South Asian children, single sex-specific-positive BMl adjustments of $+1.12 \mathrm{~kg} \mathrm{~m}^{-2}$ for boys and $+1.07 \mathrm{~kg} \mathrm{~m}^{-2}$ for girls were applicable for all age groups and body fatness levels. For Black children, negative BMI adjustments were needed which were modified by age and body fatness (Supplementary Table 1). Fuller details are provided in a previous report. ${ }^{17}$

\section{Statistical analysis}

The distributions of weight, height and BMI were reviewed for outliers. BMI was positively skewed and therefore medians rather than means were presented. Median BMI and the prevalences of specific BMI categories (underweight, normal weight, overweight, obese) defined using the UK $90^{19}$ were determined for each ethnic group and for all participants before and after the application of BMI adjustments. Mann-Whitney Utests were used to compare the distributions of BMI (or adjusted BMI) and indirectly to compare the differences in medians; $z$-tests for differences in proportions were used to compare prevalences of overweight-obesity between each of the ethnic minority groups and the White children. The prevalence of overweight-obesity was also determined for each LA in England to allow geographical comparisons to be made (including both prevalence and prevalence rankings) before and after BMI adjustment.

\section{Role of the funding source}

The funder had no role in the study design, data analysis, data interpretation or writing of the report. The authors had full access to all the data in the study and had final responsibility to submit the manuscript for publication.

\section{RESULTS}

Participants and data exclusions

In the 2012-13 school year, 1076824 children participated in NCMP. Of these, we excluded 8563 children $(0.01 \%)$ from analyses. Four children had implausible weight or height values and 324 children were outside the study age-range. A further 8235 children who were measured in LAs identified by NCMP as having data quality concerns (Redcar-Cleveland, Torbay and Middlesbrough) were excluded. Children from one further area (Bassetlaw) flagged up by NCMP for potential data quality concerns were not excluded; Bassetlaw was part of a substantially larger LA district (Nottinghamshire) without quality concerns. LA analyses specifically excluded 684 children from three LAs each with fewer than 1000 participants (The City and County of the City of London $(n=11)$, Isles of Scilly $(n=21)$ and Rutland $(n=652))$ to avoid unnecessary imprecision in the results.

\section{Characteristics of study participants}

Table 1 summarises participant characteristics for each age-sex group, including 582899 children aged 4-5 years and 485362 children aged 10-11 years from 152 LAs. Ethnicity prevalences ( $60 \%$ Whites, $\sim 5 \%$ Blacks, $\sim 8 \%$ South Asians) did not differ 


\begin{tabular}{|c|c|c|c|c|c|c|c|}
\hline \multirow[t]{2}{*}{ Ethnic group } & \multirow[t]{2}{*}{$\mathrm{N}$} & \multirow{2}{*}{$\begin{array}{c}\text { Median BMI, } \\
\mathrm{kg} \mathrm{m}^{-2}(L Q-U Q)\end{array}$} & \multicolumn{4}{|c|}{ 4-5-year-old boys prevalence, \% (95\% Cl) } & \multirow[t]{2}{*}{ Overweight-obese } \\
\hline & & & Underweight & Healthy & Overweight & Obese & \\
\hline \multicolumn{8}{|l|}{ Before BMI adjustment } \\
\hline White & 197691 & $16.0(15.3-16.9)$ & $0.7(0.6-0.7)$ & $76.3(76.1-76.5)$ & $14.1(13.9-14.2)$ & $8.9(8.8-9.1)$ & $23.0(22.8-23.2)$ \\
\hline Black Caribbean & 2838 & $16.0(15.2-17.0)$ & $0.9(0.6-1.3)$ & $74.3(72.7-76.0)$ & $13.2(12.0-14.5)$ & $11.5(10.3-12.7)$ & $24.7(23.1-26.3)$ \\
\hline Black-other & 2627 & $16.2(15.3-17.2)$ & $1.6(1.1-2.0)$ & $69.1(67.4-70.9)$ & $14.0(12.7-15.3)$ & $15.3(13.9-16.7)$ & $29.3(27.6-31.1)$ \\
\hline South Asian & 23191 & $15.5(14.6-16.6)$ & $4.3(4.1-4.6)$ & $76.3(75.8-76.9)$ & $8.3(8.0-8.7)$ & $11.0(10.6-11.4)$ & $19.3(18.8-19.9)$ \\
\hline South Asian-Indian & 7474 & $15.3(14.4-16.3)$ & $6.1(5.5-6.6)$ & 77.6 (76.7-78.6) & $7.1(6.6-7.7)$ & $9.2(8.5-9.8)$ & $16.3(15.5-17.1)$ \\
\hline South Asian-Pakistani & 11502 & $15.5(14.7-16.6)$ & $3.7(3.3-4.0)$ & $75.9(75.1-76.7)$ & $9.1(8.5-9.6)$ & $11.4(10.8-12.0)$ & $20.4(19.7-21.2)$ \\
\hline South Asian - Bangladeshi & 4215 & $15.6(14.7-16.7)$ & $3.1(0.1-0.2)$ & $75.2(73.9-76.5)$ & $8.5(7.7-9.4)$ & $13.2(12.2-14.2)$ & $21.8(20.5-23.0)$ \\
\hline Other Asian & 6184 & $15.7(14.9-16.8)$ & $2.6(2.2-3.0)$ & $75.9(74.8-76.9)$ & $10.7(9.9-11.5)$ & $10.8(10.1-11.6)$ & $21.5(20.5-22.5)$ \\
\hline \multicolumn{8}{|l|}{ White } \\
\hline Black & & $15.1(14.4-15.9)$ & $4.3(4.0-4.7)$ & $85.1(84.5-85.7)$ & $5.8(5.4-6.1)$ & $4.8(4.4-5.1)$ & $10.5(10.0-11.0)$ \\
\hline Black African & & $15.2(14.4-16.9)$ & $4.1(3.7-4.5)$ & $84.1(83.4-84.9)$ & $6.4(5.9-6.9)$ & $5.4(4.9-5.8)$ & $11.8(11.1-12.4)$ \\
\hline Black Caribbean & & $15.0(14.3-15.7)$ & $4.2(3.4-4.9)$ & $88.5(87.4-89.7)$ & $4.4(3.6-5.1)$ & $2.9(2.3-3.5)$ & $7.3(6.3-8.3)$ \\
\hline Black-Other & & $15.1(14.4-15.9)$ & $5.3(4.4-6.1)$ & $84.8(83.5-86.2)$ & $5.0(4.2-5.8)$ & $4.9(4.0-5.7)$ & $9.9(8.7-11.0)$ \\
\hline South Asian & & $16.6(15.7-17.7)$ & $0.2(0.2-0.3)$ & $60.4(59.8-61.1)$ & $18.4(17.9-18.9)$ & $21.0(20.5-21.5)$ & $39.4(38.7-40.0)$ \\
\hline South Asian-Indian & & $16.4(15.5-17.5)$ & $0.3(0.2-0.4)$ & $65.2(64.1-66.3)$ & $16.7(15.9-17.5)$ & $17.8(16.9-18.7)$ & $34.5(33.4-35.6)$ \\
\hline South Asian-Pakistani & & $16.6(15.8-17.8)$ & $0.2(0.1-0.2)$ & $58.5(57.6-59.4)$ & $19.2(18.5-19.9)$ & $22.2(21.4-23.0)$ & $41.4(40.5-42.3)$ \\
\hline South Asian-Bangladeshi & & $16.7(15.8-17.9)$ & $0.2(0.1-0.4)$ & $57.4(55.9-58.9)$ & $19.1(18.0-20.3)$ & $23.3(22.0-24.5)$ & $42.4(40.9-43.9)$ \\
\hline \multicolumn{8}{|c|}{ 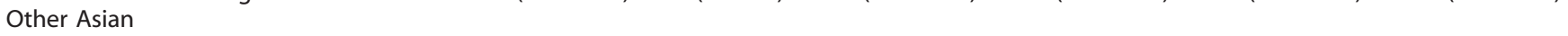 } \\
\hline \multicolumn{8}{|l|}{ Other ethnicity } \\
\hline \multicolumn{8}{|l|}{ Unknown } \\
\hline Overall & & $16.0(15.2-16.9)$ & $0.9(0.9-1.0)$ & $75.3(75.2-75.5)$ & $13.8(13.7-13.9)$ & $10.0(9.8-10.1)$ & $23.7(23.6-23.9)$ \\
\hline
\end{tabular}

appreciably by age-sex group. Data on ethnicity were not available for $\sim 13 \%$ of $4-5$ year olds and $\sim 16 \%$ of $10-11$ year olds. As expected, older children were heavier and taller on average and had higher median BMls. At 4-5 years, boys were heavier and taller than girls, with a marginally higher median $\mathrm{BMl}$; at 10-11 years, girls were heavier and taller than boys and had a higher median BMI.

Median BMI and prevalences of overweight, obesity and overweight-obesity by ethnicity: effect of BMI adjustments Median BMI and prevalences of BMI categories by ethnicity before and after BMI adjustment are shown for 4-5 year olds in Tables 2 and 3 and for 10-11 year olds in Tables 4 and 5. In White children, the prevalences of overweight-obesity (boys, girls) were $23.0 \%$ and $20.9 \%$ in $4-5$ year olds, $32.8 \%$ and $30.4 \%$ in $10-11$ year olds, respectively.

Black children. Before BMI adjustment, Black children had higher median BMI than Whites for all age-sex groups (Mann-Whitney $U$ tests, all $P<0.0001$ ). The prevalences of overweight-obesity and obesity were higher than those of White children, both for boys and girls at $4-5$ years and at 10-11 years ( $z$-tests, all $P<0.0001$ ). However, after adjustment, Black children aged 4-5 years (both boys and girls) and 10-11-year-old boys had slightly lower median adjusted BMI whilst Black 10-11-year-old girls had higher adjusted BMI (compared with Whites) (Mann-Whitney U-tests, all $P<0.0001)$. Overweight-obesity prevalences were slightly lower in Black children aged $4-5$ years (both boys and girls) ( $z$-tests, both $P<0.0001$ ) and in 10-11-year-old boys ( $z$-test, $P=0.04)$. However, black girls aged 10-11 years had a higher overweight-obesity prevalence than their White peers ( $z$-test, $P<0.0001)$. There were no consistent differences in median adjusted BMI and overweightobesity prevalence between Black African, Black Caribbean and other Black children either before or after adjustment.

South Asian children. before BMI adjustment, BMI patterns in South Asian children differed by age group. At 4-5 years, median BMI was lower in South Asians than in White children (MannWhitney $U$-tests, both $P<0.0001)$. Overweight-obesity prevalences were also lower in 4-5-year-old South Asians than in White children ( $z$-tests, both $P<0.0001$ ). At 10-11 years, South Asian boys had an appreciably higher median BMI than Whites (MannWhitney $U$-test, $P<0.0001$ ) but there was no marked difference in girls (Mann-Whitney $U$-test, $P=0.77$ ). However, overweightobesity prevalences for both boys and girls were higher than White children ( $z$-test, both $P<0.0001$ ). After adjustment, South Asian children (boys and girls), both at 4-5 years and more so at 10-11 years, had higher median BMls (Mann-Whitney U-tests, all $P<0.0001$ ); they also had higher overweight-obesity prevalences than White children ( $z$-tests, all $P<0.0001$ ); more than half of older South Asian boys were overweight-obese. Within the South Asian group, children of Pakistani and Bangladeshi origin had higher median adjusted BMI, obesity and overweight-obesity 
Table 3. 4-5-year-old girls-summary of body mass index and weight categories using UK90 population thresholds ${ }^{\mathrm{a}}$ by ethnic group before and after ethnic adjustments to BMI in the national child measurement programme (2012-13)

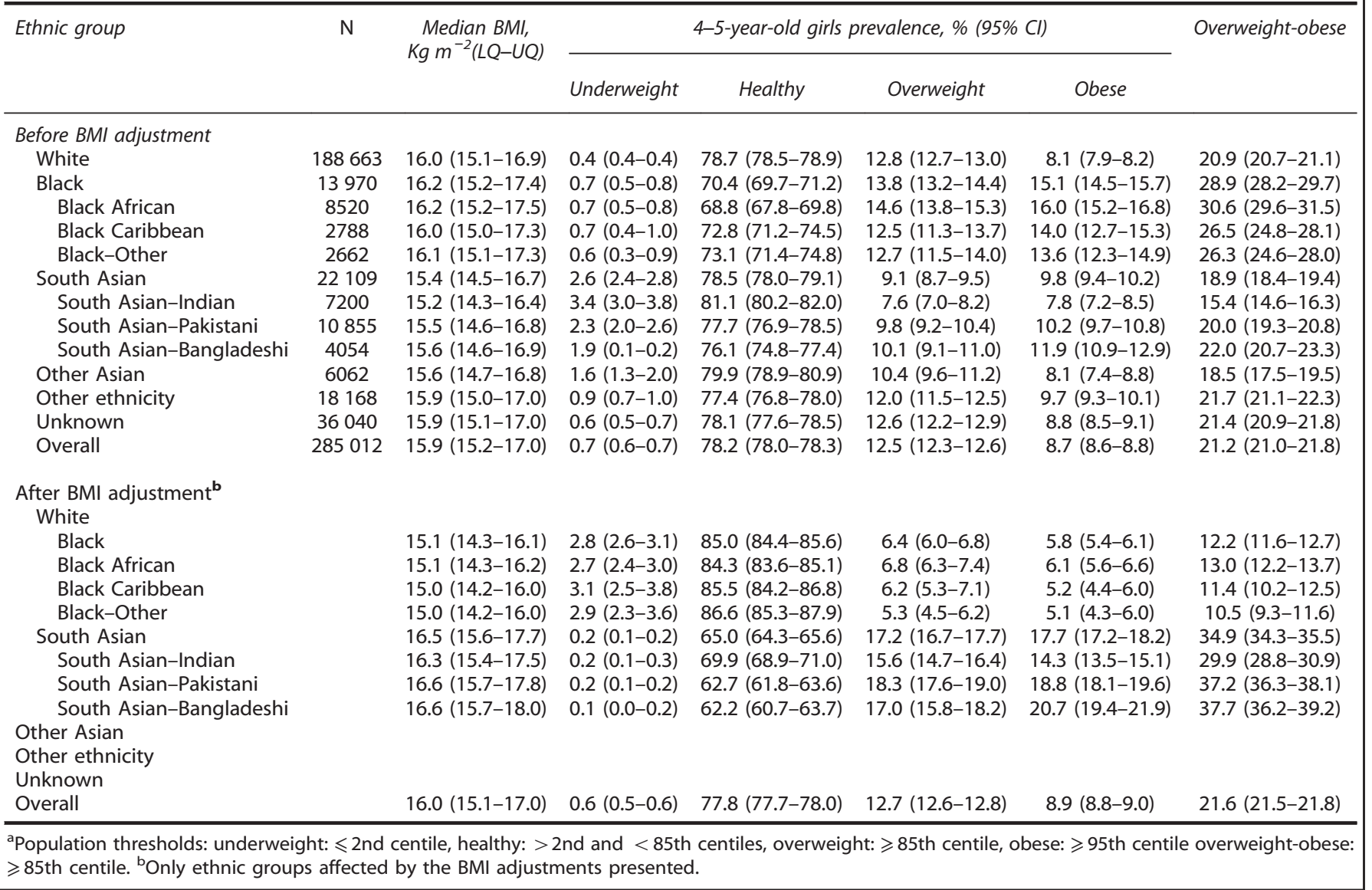

prevalences than children of Indian origin; these patterns were observed for both boys and girls.

Prevalences of underweight and healthy weight by ethnicity: effect of BMI adjustments

Unadjusted underweight prevalences were higher in younger Black children and similar in older Black children compared with Whites; South Asian children had higher unadjusted prevalences of underweight in both age groups. However, after adjustment Black children had even higher, and South Asian children lower, underweight prevalences. Unadjusted healthy weight prevalences were lower in Black children (younger and older) compared with Whites; younger South Asian children had similar unadjusted healthy weight prevalences to Whites, while older children had lower prevalences. However, adjusted prevalences of healthy weight were markedly higher in Black children and markedly lower in South Asian children compared with White children.

Overall median BMI and prevalences of weight categories: effect of BMI adjustments

The effects of ethnic-specific BMI adjustments on overall BMI and overweight-obesity patterns in the NCMP population were also examined (Table 2-5). After BMI adjustment, overall population median BMI values and the prevalences of being underweight or healthy changed very little. The adjusted overall prevalences of overweight-obesity were marginally increased in all age-sex groups, all by $0.5 \%$ or less.
LA differences in overall overweight-obesity prevalence: effect of BMI adjustments

The effects of BMI adjustment on the prevalences and rankings of overweight-obesity in LA areas were examined. Prevalences of overweight-obesity in LA areas before and after BMI adjustments are plotted against one another in Figure 1, for each age-sex group. LA variations in overweight-obesity prevalence were marked in 10-11 year olds (20-50\%); the Spearman rank correlations of unadjusted and adjusted prevalence were high both for boys and girls (both $\rho=0.96$ ). LA variations in overweightobesity prevalence were smaller in 4-5-year-old boys and girls (15-30\%) and correlations between unadjusted and adjusted prevalence were weaker ( $r=0.62,0.74$, respectively). After adjustment, overweight-obesity prevalences in LAs with a high South Asian population prevalence $(\geqslant 20 \%)$ were systematically higher, whereas prevalences in LAs with a high Black population prevalence $(\geqslant 20 \%)$ were systematically lower. In the small number of LAs with a high population prevalence of both ethnicities, adjustment had little effect on overweight-obesity prevalences (Figure 1). However, the effects of BMI adjustment on LA rankings were substantial. The 20 LAs with the highest overweight-obesity prevalences both before and after BMI adjustment in each agesex group are summarised in supplementary Figures 1-4. In 4-5 year olds, more than half of the 20 LAs with high overweightobesity rankings were different after BMI adjustment; in 10-11 year olds, at least a quarter were different. After adjustment, more LA areas with a high South Asian population prevalence were 
Table 4. 10-11-year-old boys-summary of body mass index and weight categories using UK90 population thresholds ${ }^{\mathrm{a}}$ by ethnic group before and after ethnic adjustments to BMI in the national child measurement programme (2012-13)

\begin{tabular}{|c|c|c|c|c|c|c|c|}
\hline \multirow[t]{2}{*}{ Ethnic group } & \multirow[t]{2}{*}{$\mathrm{N}$} & \multirow{2}{*}{$\begin{array}{c}\text { Median BMl, } \mathrm{Kg} \mathrm{m}^{-2} \\
(L Q-U Q)\end{array}$} & \multicolumn{4}{|c|}{ 10-11-year-old boys prevalence, \% (95 Cl) } & \multirow{2}{*}{$\begin{array}{l}\text { Overweight- } \\
\text { obese }\end{array}$} \\
\hline & & & Underweight & Healthy & Overweight & Obese & \\
\hline White & 160278 & $17.8(16.3-20.1)$ & $0.9(0.8-0.9)$ & $66.3(66.1-66.5)$ & $14.1(14.0-14.3)$ & $18.7(18.5-18.9)$ & $32.8(32.6-33.1)$ \\
\hline Black & 11347 & $18.5(16.7-21.4)$ & $0.9(0.7-1.1)$ & $56.9(56.0-57.8)$ & $15.4(14.8-16.1)$ & $26.8(26.0-27.6)$ & $42.2(41.3-43.1)$ \\
\hline Black African & 6172 & $18.6(16.7-21.4)$ & $1.0(0.8-1.3)$ & $55.8(54.6-57.1)$ & $15.9(15.0-16.8)$ & $27.2(26.1-28.3)$ & $43.1(41.9-44.4)$ \\
\hline South Asian-Indian & 5817 & $18.1(15.9-21.1)$ & $4.6(4.0-5.1)$ & $55.9(54.6-57.2)$ & $14.8(13.9-15.7)$ & $24.7(23.6-25.8)$ & $39.5(38.3-40.8)$ \\
\hline South Asian-Pakistani & 9675 & $18.3(16.0-21.4)$ & $3.8(3.5-4.2)$ & $54.9(53.9-55.9)$ & $14.5(13.8-15.2)$ & $26.7(25.9-27.6)$ & $41.2(40.2-42.2)$ \\
\hline $\begin{array}{l}\text { South Asian- } \\
\text { Bangladeshi }\end{array}$ & 3914 & $18.8(16.3-22.0)$ & $1.8(0.3-0.6)$ & $51.8(50.2-53.4)$ & $15.4(14.2-16.5)$ & $31.0(29.6-32.5)$ & $46.4(44.8-48.0)$ \\
\hline Other Asian & 4325 & $18.4(16.3-21.3)$ & $2.4(1.9-2.8)$ & $55.2(53.7-56.7)$ & $15.8(14.8-16.9)$ & $26.6(25.3-27.9)$ & $42.4(41.0-43.9)$ \\
\hline Other ethnicity & 12914 & $18.2(16.4-20.9)$ & $1.0(0.9-1.2)$ & $60.1(59.3-60.9)$ & $15.2(14.6-15.9)$ & $23.6(22.9-24.4)$ & $38.9(38.0-39.7)$ \\
\hline \multicolumn{8}{|l|}{$\begin{array}{l}\text { After BMI adjustment }{ }^{\mathrm{b}} \\
\text { White }\end{array}$} \\
\hline Black & & $17.6(16.0-21.1)$ & $2.1(1.8-2.4)$ & $66.0(65.1-66.9)$ & $13.4(12.8-14.0)$ & $18.5(17.8-19.2)$ & $31.9(31.0-32.8)$ \\
\hline Black African & & $17.7(16.0-20.1)$ & $2.2(1.8-2.6)$ & $65.6(64.4-66.8)$ & $13.5(12.7-14.4)$ & $18.7(17.7-19.7)$ & $32.2(31.0-33.4)$ \\
\hline Black Caribbean & & $17.4(16.0-20.0)$ & $1.7(1.2-2.2)$ & $66.3(64.6-68.0)$ & $13.0(11.8-14.2)$ & $18.9(17.5-20.4)$ & $31.9(30.3-33.6)$ \\
\hline Black-Other & & $17.5(16.0-20.0)$ & $2.4(1.7-3.0)$ & $66.7(64.7-68.6)$ & $13.7(12.3-15.1)$ & $17.3(15.7-18.9)$ & $31.0(29.1-32.9)$ \\
\hline South Asian & & $19.4(17.1-22.6)$ & $0.4(0.3-0.5)$ & $47.5(46.8-48.2)$ & $16.7(16.2-17.3)$ & $35.4(34.7-36.1)$ & $52.1(51.4-52.9)$ \\
\hline South Asian-Indian & & $19.2(17.0-22.2)$ & $0.4(0.2-0.5)$ & $49.5(48.3-50.8)$ & $16.8(15.9-17.8)$ & $33.3(32.1-34.5)$ & $50.1(48.8-51.4)$ \\
\hline South Asian-Pakistani & & $19.4(17.1-22.5)$ & $0.5(0.3-0.6)$ & $48.1(47.1-49.1)$ & $16.4(15.7-17.2)$ & $35.0(34.1-36.0)$ & $51.5(50.5-52.5)$ \\
\hline $\begin{array}{l}\text { South Asian- } \\
\text { Bangladeshi }\end{array}$ & & $19.9(17.5-23.1)$ & $0.2(0.0-0.3)$ & $42.9(41.3-44.4)$ & $17.4(16.2-18.6)$ & $39.5(38.0-41.1)$ & $56.9(55.4-58.5)$ \\
\hline \multicolumn{8}{|l|}{$\begin{array}{l}\text { Bangladeshı } \\
\text { Other Asian }\end{array}$} \\
\hline \multicolumn{8}{|l|}{ Other ethnicity } \\
\hline Unknown & & & & & & & \\
\hline Overall & & $17.9(16.4-20.4)$ & $0.9(0.9-1.0)$ & $64.0(63.8-64.2)$ & $14.5(14.3-14.6)$ & $20.6(20.5-20.8)$ & $35.1(34.9-35.3)$ \\
\hline
\end{tabular}

present in the top 20 rankings, whereas the number of LA areas with a high Black population prevalence declined (Supplementary Figures 1-4). A complete summary of LA overweight-obesity prevalences before and after BMI adjustment for each age-sex group is presented in Supplementary Table 2; corresponding information on overweight-obesity prevalence rankings is presented in Supplementary Table 3.

\section{Sensitivity analyses}

To determine whether results were influenced by children with particularly high unadjusted BMI values, sensitivity analyses excluded children with severe obesity $(n=14087)$, defined using age and sex-specific Extended International Obesity Task Force thresholds. ${ }^{21}$ The results were not materially affected by excluding these individuals. The results were also examined using more extreme overweight-obesity definitions, those based on the use of NCMP clinical reporting thresholds (on or above the 91st percentile). The patterns of ethnic differences in overweightobesity prevalence were not materially changed by the use of more extreme thresholds (Supplementary Table 4).

\section{DISCUSSION}

In this study, the first to our knowledge using ethnic-specific BMI adjustments to obtain an accurate picture of the relative prevalences of overweight-obesity in English children of different ethnicity, adjusted childhood overweight-obesity prevalence was particularly high among South Asian children in all age-sex groups and among older Black girls. These patterns were markedly different from those based on unadjusted BMI data, in which higher overweight-obesity prevalences in Black children were apparent. BMI adjustment increased the prevalences and rankings of overweight-obesity in LAs with high South Asian representation $(\geqslant 20 \%)$ and reduced them in LAs with high Black representation.

Relation to previous studies

In the present investigation, unadjusted median BMI and overweight-obesity prevalences were particularly high in Black children compared with Whites, both at 4-5 years and at 10-11 years. This is consistent with previous NCMP reports from the same $^{13}$ and previous years, ${ }^{22}$ and with BMI data from other nationally representative studies, including the Health Survey for England ${ }^{7}$ and the Millennium Cohort Study both at 5 years ${ }^{23}$ and 11 years. $^{24}$ The unadjusted BMI patterns in South Asian children, with lower unadjusted median BMI and overweight-obesity prevalences than Whites at 4-5 years but higher prevalences at 10-11 years, are also consistent with NCMP data from the same ${ }^{13}$ and previous years ${ }^{22}$ and with reports from the Millennium Cohort Study. ${ }^{23,24}$ The markedly higher adjusted median BMI and overweight-obesity prevalences levels observed among South Asian children at both 4-5 and 10-11 years are consistent with the results of other population-based studies using more direct body 
Table 5. 10-11-year-old girls-summary of body mass index and weight categories using UK90 population thresholds ${ }^{\mathrm{a}}$ by ethnic group before and after ethnic adjustments to BMI in the national child measurement programme (2012-13)

\begin{tabular}{|c|c|c|c|c|c|c|c|}
\hline \multirow[t]{2}{*}{ Ethnic group } & \multirow[t]{2}{*}{$\mathrm{N}$} & \multirow{2}{*}{$\begin{array}{c}\text { Median BMI, } \\
K_{g} \mathrm{~m}^{-2}(L Q-U Q)\end{array}$} & \multicolumn{4}{|c|}{ 10-11 -year-old girls prevalence, \% (95 Cl) } & \multirow[t]{2}{*}{ Overweight-obese } \\
\hline & & & Underweight & Healthy & Overweight & Obese & \\
\hline White & 151146 & $18.3(16.5-20.8)$ & $1.2(1.1-1.3)$ & $68.4(68.1-68.6)$ & $14.2(14.0-14.4)$ & $16.2(16.0-16.4)$ & $30.4(30.2-30.7)$ \\
\hline Black & 11319 & $19.6(17.3-22.7)$ & $1.3(1.1-1.5)$ & $54.1(53.2-55.0)$ & $17.2(16.5-17.9)$ & $27.4(26.6-28.2)$ & $44.6(43.7-45.5)$ \\
\hline Black African & 6154 & $19.6(17.3-22.7)$ & $1.4(1.1-1.7)$ & $53.5(52.3-54.8)$ & $17.5(16.6-18.5)$ & $27.5(26.4-28.6)$ & $45.0(43.8-46.3)$ \\
\hline Black Caribbean & 2927 & $19.6(17.2-22.8)$ & $1.0(0.6-1.3)$ & $54.2(52.4-56.0)$ & $16.3(14.9-17.6)$ & $28.6(27.0-30.2)$ & $44.9(43.1-46.7)$ \\
\hline South Asian-Indian & 5493 & $18.0(15.9-20.9)$ & $5.2(4.6-5.7)$ & $64.4(63.1-65.7)$ & $14.3(13.4-15.3)$ & $16.1(15.1-17.1)$ & $30.4(29.2-31.7)$ \\
\hline South Asian-Pakistani & 9322 & $18.6(16.2-21.6)$ & $4.2(3.8-4.6)$ & $60.3(59.3-61.3)$ & $14.7(14.0-15.4)$ & $20.7(19.9-21.5)$ & $35.4(34.5-36.4)$ \\
\hline South Asian-Bangladeshi & 3821 & $18.7(16.4-21.8)$ & $2.2(0.5-0.8)$ & $61.1(59.5-62.6)$ & $15.0(13.9-16.1)$ & $21.7(20.4-23.1)$ & $36.7(35.2-38.3)$ \\
\hline Other Asian & 41745 & $18.2(16.2-20.6)$ & $2.7(2.2-3.2)$ & $68.3(66.9-69.7)$ & $14.1(13.1-15.2)$ & $14.8(13.8-15.9)$ & $29.0(27.6-30.3)$ \\
\hline Other ethnicity & 12547 & $18.7(16.6-21.6)$ & $1.7(1.5-2.0)$ & $62.5(61.7-63.4)$ & $14.9(14.3-15.5)$ & $20.8(20.1-21.5)$ & $35.7(34.9-36.6)$ \\
\hline Unknown & 38756 & $18.3(16.5-20.9)$ & $1.5(1.3-1.6)$ & $67.4(67.0-67.9)$ & $14.2(13.8-14.5)$ & $16.9(16.6-17.3)$ & $31.1(30.7-31.6)$ \\
\hline Overall & 236579 & $18.3(16.5-21.0)$ & $1.5(1.5-1.6)$ & $66.7(66.5-66.9)$ & $14.4(14.3-14.6)$ & $17.3(17.2-17.5)$ & $31.8(31.6-32.0)$ \\
\hline Black African & & $18.7(16.6-21.4)$ & $2.3(1.9-2.7)$ & $62.6(61.4-63.8)$ & $16.0(15.0-16.9)$ & $19.1(18.1-20.1)$ & $35.1(33.9-36.2)$ \\
\hline Black Caribbean & & $18.6(16.5-21.5)$ & $1.7(1.2-2.2)$ & $62.7(61.0-64.5)$ & $15.4(14.1-16.7)$ & $20.2(18.7-21.6)$ & $35.6(33.8-37.3)$ \\
\hline Black-Other & & $18.4(16.4-21.1)$ & $2.4(1.8-3.0)$ & $64.5(62.5-66.5)$ & $15.4(13.9-16.9)$ & $17.7(16.1-19.3)$ & $33.1(31.1-35.0)$ \\
\hline South Asian & & $19.5(17.2-22.5)$ & $0.6(0.5-0.7)$ & $55.8(55.1-56.5)$ & $17.3(16.7-17.8)$ & $26.4(25.7-27.0)$ & 43.6 (42.9-44.3) \\
\hline South Asian-Indian & & $19.1(17.0-21.9)$ & $0.8(0.5-1.0)$ & $59.6(58.3-60.9)$ & $17.1(16.1-18.1)$ & $22.6(21.5-23.7)$ & 39.7 (38.4-41.0) \\
\hline South Asian-Pakistani & & $19.6(17.2-22.6)$ & $0.7(0.5-0.8)$ & $54.7(53.7-55.7)$ & $17.1(16.4-17.9)$ & $27.5(26.6-28.4)$ & $44.7(43.7-45.7)$ \\
\hline South Asian-Bangladeshi & & $19.8(17.5-22.9)$ & $0.3(0.2-0.5)$ & $53.0(51.4-54.6)$ & $17.7(16.5-19.0)$ & $28.9(27.5-30.4)$ & $46.7(45.1-48.2)$ \\
\hline \multicolumn{8}{|c|}{ 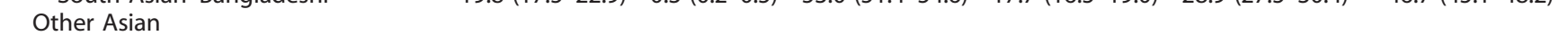 } \\
\hline \multicolumn{8}{|l|}{ Other ethnicity } \\
\hline Unknown & & & & & & & \\
\hline Overall & & $18.4(16.5-21.1)$ & $1.3(1.3-1.3)$ & $66.7(66.5-66.8)$ & $14.6(14.4-14.7)$ & $17.5(17.3-17.6)$ & $32.0(31.9-32.2)$ \\
\hline
\end{tabular}

fatness measures, including bioimpedance and skinfold thickness in $9-10$ year olds, ${ }^{15}$ deuterium dilution in both $8-10$ year olds ${ }^{16}$ and 5-11 year olds ${ }^{25}$ and dual energy X-ray absorptiometry in 518 year olds, ${ }^{26}$ all of which showed higher body fatness in South Asians than in Whites. The lower adjusted median BMI and overweight-obesity prevalences observed in all Black children (except older girls) are also consistent with the results of earlier studies using more direct body fatness measures, including bioimpedance and skinfold thickness in 9-10 year olds, ${ }^{15}$ deuterium dilution in 8-10 year olds ${ }^{16}$ and dual energy X-ray absorptiometry in 5-18 year olds, ${ }^{26}$ which all showed lower body fatness in Blacks than in Whites. Our results reinforce the conclusion of an earlier systematic review that observed ethnic patterns of childhood overweight-obesity are strongly dependent on the method used to assess overweight-obesity. ${ }^{27}$

\section{Implications}

Our results, based on adjustment of BMI values to achieve consistent BMI-body fatness associations in South Asian, Black and White children, provide strong evidence that English South Asian children (especially Bangladeshis and Pakistanis) have elevated overweight-obesity burdens. This is a particular concern, given the high long-term risks of type 2 diabetes and cardiovascular disease in UK South Asians ${ }^{7,8}$ from childhood. ${ }^{11,12} \mathrm{~A}$ second concern is the high adjusted BMI values in older Black girls, which suggest that the patterning of high obesity prevalence in UK Black women ${ }^{7}$ is emerging between $4-5$ and $10-11$ years, again with implications for the focus of prevention in young age groups. The average differences in adjusted BMI of $>1 \mathrm{~kg} \mathrm{~m}^{-2}$ (for example between South Asians and Whites at 10-11 years) would (if sustained into adulthood, which appears likely on current trends) account for appreciably higher risks of both T2D (by at least $25 \%)^{28}$ and CHD (by at least $5 \%)^{5,29}$ the impact of higher BMI from childhood on T2D risk is likely to be particularly marked. ${ }^{6}$ The results also reinforce earlier concerns that unadjusted BMI data may disproportionately misclassify weight status in South Asian and Black children. ${ }^{14-16,25}$ This report emphasises the scale of potential misclassification, showing that while unadjusted BMI data point to an excess of overweight-obesity in Black children, in reality the excess is greater in South Asian children-though overall overweight-obesity prevalences in the entire population of England are little affected, as the changes in South Asian and Black children tend to offset one another. The results also draw attention to uncertainties in overweight-obesity prevalence estimates at LA level, which have been reported annually by NCMP. ${ }^{13}$ These LA prevalence estimates are very sensitive to BMI adjustments and are particularly (and predictably) affected in LAs with high ethnic minority prevalences. Adjustment reduced overweight-obesity prevalence rankings in LAs with substantial Black representation and increased them in LAs with substantial South Asian populations. This underscores the need to treat LA rankings cautiously, and emphasise instead the widespread occurrence of childhood overweight-obesity in all English LAs; even among the lowest ranking LAs, overweight-obesity prevalences are excessive. Effective population-wide strategies for overweight-obesity prevention are therefore needed in all children, with a special emphasis on South Asian children and 
older Black girls. Although the present analyses focus on English children, the results are likely to be relevant for the UK as a whole. Moreover, they are likely to have relevance for other countries with substantial South Asian and African origin ethnic minority populations and could also have relevance for other ethnic minority populations (for example, Pacific Island populations) with different BMI-body fatness associations from those of majority White populations. ${ }^{30,31}$

\section{Strengths and limitations}

The NCMP is a large-scale, national survey resource with high rates of participation both by schools and individual children, with standardised data collection and quality control procedures. We used 2012-13 data, the latest year available to us. The validity of the BMI adjustments used is critical; these used the reference deuterium dilution method ${ }^{32}$ to obtain fat mass estimates based on a pooled resource of $\sim 1750$ Black, South Asian and White children. The BMI distributions of the South Asian, Black and White children in the studies used to derive BMI adjustments were very similar to those of the children in NCMP populations, suggesting that their application to NCMP data was appropriate. BMI adjustments were provided for South Asian and Black children (based on inclusion of Indian, Pakistani, Bangladeshi, Black African and Caribbean children); these groups together account for almost two-thirds of all ethnic minority participants in the NCMP. However, it was not possible to provide adjustments for other ethnic groups not represented in the deuterium studies, including children with mixed ethnicities. It is however possible that the adjustments derived for South Asian children could be applied to Other Asians, ${ }^{14}$ which would increase their estimated overweightobesity burden. The validity of BMI adjustments could be greater if they could be standardised in relation to visceral fat (rather than total body fat), which is particularly implicated in the development of insulin resistance and type 2 diabetes risk and may be particularly high in South Asians. ${ }^{8}$ Although the validity and practicability of such adjustments remains uncertain, the current adjustments for South Asians may be conservative, potentially underestimating their true burden of overweight-obesity.

\section{CONCLUSION}

There is a substantial excess of overweight-obesity among English South Asian children (both at 4-5 years and especially at 10-11 years) and among Black girls aged 10-11 years, with important implications for overweight-obesity prevention. These patterns are not apparent using unadjusted BMI data, which tend to underestimate overweight-obesity prevalences in South Asian children and overestimate them in Black children.

\section{CONFLICT OF INTEREST}

The authors declare no conflict of interest.

\section{ACKNOWLEDGEMENTS}

We are grateful to Mary S Fewtrell, Dalia Haroun, Sooky Lum and Jane E Williams for providing deuterium dilution data in support of this research. We acknowledge The Health and Social Care Information Centre (now NHS Digital) for providing NCMP data. This work was supported by a project grant from the British Heart Foundation (Grant ref: PG/15/19/31336) and by the National Institute for Health Research (NIHR) Collaboration for Leadership in Applied Health Research and Care (South London). CMN was supported by the Wellcome Trust Institutional Strategic Support Fund awarded to St. George's, University of London (204809/Z/16/Z). HR was part supported by the National Institute for Health Research (NIHR) Collaboration for Leadership in Applied Health Research and Care (CLAHRC) North Thames at Bart's Health NHS Trust. The views expressed are those of the authors and not necessarily those of the funding agencies, the NHS or the Department of Health.

\section{AUTHOR CONTRIBUTIONS}

Study design-MTH, CMN, PHW, CGO, ARR, DGC, JCKW. Data analysis-MTH, ARR, DGC, CMN. Data interpretation-MTH, PHW, ARR, CGO, DGC, JCKW, HR, CMN. Draughting manuscript-MTH, PHW. Critical evaluation and revision of manuscript-MTH, CMN, PHW, ASD, CGO, ARR, DGC, JCKW, HRW.

\section{REFERENCES}

1 World Health Organisation. Childhood overweight and obesity 2014. [Available from www.who.int/dietphysicalactivity/childhood/en/.

2 Bridges S, Darton R, Evans-Lacko S, Fuller E, Henderson C, llic N et al. Health Survey for England 2014. Joint Health Surveys Unit [http://content.digital.nhs.uk/ catalogue/PUB19295]. 2015.

3 Cole TJ, Bellizzi MC, Flegal KM, Dietz WH. Establishing a standard definition for child overweight and obesity worldwide: international survey. BMJ 2000; 320: 1240-1243.

4 Tirosh A, Shai I, Afek A, Dubnov-Raz G, Ayalon N, Gordon B et al. Adolescent BMI trajectory and risk of diabetes versus coronary disease. N Engl J Med 2011; 364: 1315-1325.

5 Owen CG, Whincup PH, Orfei L, Chou QA, Rudnicka AR, Wathern AK et al. Is body mass index before middle age related to coronary heart disease risk in later life? Evidence from observational studies. Int J Obesity 2009; 33: 866-877.

6 Narayan KM, Boyle JP, Thompson TJ, Gregg EW, Williamson DF. Effect of BMI on lifetime risk for diabetes in the U.S. Diabetes Care 2007; 30: 1562-1566.

7 The Health and Social Care Information Centre. Health Survey for England 2004: The health of ethnic minority groups. [http://content.digital.nhs.uk/catalogue/ PUB01209/heal-surv-hea-eth-min-hea-tab-eng-2004-rep.pdf]; 2006.

8 Tillin T, Hughes AD, Godsland IF, Whincup PH, Forouhi NG, Welsh P et al. Insulin resistance and truncal obesity as important determinants of the greater incidence of diabetes in Indian Asians and African Caribbeans compared with Europeans: the Southall And Brent REvisited (SABRE) cohort. Diabetes Care 2013; 36: 383-393.

9 Tillin T, Hughes AD, Mayet J, Whincup PH, Sattar N, Forouhi NG et al. The relationship between metabolic risk factors and incident cardiovascular disease in Europeans, South Asians, and African Caribbeans: SABRE (Southall and Brent Revisited) -- a prospective population-based study. J Am Coll Cardiol 2013; 61: 1777-1786.

10 Wild SH, Fischbacher C, Brock A, Griffiths C, Bhopal R. Mortality from all causes and circulatory disease by country of birth in England and Wales 2001-2003. J Public Health 2007; 29: 191-198.

11 Whincup PH, Nightingale CM, Owen CG, Rudnicka AR, Gibb I, McKay CM et al. Early emergence of ethnic differences in type 2 diabetes precursors in the UK: the Child Heart and Health Study in England (CHASE Study). PLoS Med 2010; 7: e1000263.

12 Whincup PH, Gilg JA, Papacosta O, Seymour C, Miller GJ, Alberti KG et al. Early evidence of ethnic differences in cardiovascular risk: cross sectional comparison of British South Asian and white children. BMJ 2002; 324: 635.

13 The Health and Social Care Information Centre. National Child Measurement Programme: England, 2012-2013 year. [http://content.digital.nhs.uk/catalogue/ PUB03034/nati-chil-meas-prog-eng-2010-2011-rep1.pdf]; 2014.

14 World Health Organisation. Appropriate body-mass index for Asian populations and its implications for policy and intervention strategies. Lancet 2004; 363: 157-163.

15 Nightingale CM, Rudnicka AR, Owen CG, Cook DG, Whincup PH. Patterns of body size and adiposity among UK children of South Asian, black African-Caribbean and white European origin: Child Heart And health Study in England (CHASE Study). Inter J Epidemiol 2011; 40: 33-44.

16 Nightingale CM, Rudnicka AR, Owen CG, Donin AS, Newton SL, Furness CA et al. Are ethnic and gender specific equations needed to derive fat free mass from bioelectrical impedance in children of South asian, black african-Caribbean and white European origin? Results of the assessment of body composition in children study. PLOS ONE 2013; 8: e76426.

17 Hudda MT, Nightingale CM, Donin AS, Fewtrell MS, Haroun D, Lum S et al. Body mass index adjustments to increase the validity of body fatness assessment in UK Black African and South Asian children. Int J Obesity 2017; 41: 1048-1055.

18 Public Health England. National child measurement programme: operational guidance. [https://www.gov.uk/government/uploads/system/uploads/attachment_ data/file/377902/NCMP_operational_guidance.pdf]; 2016.

19 Cole TJ, Freeman JV, Preece MA. Body mass index reference curves for the UK, 1990. Arch Dis Child 1995; 73: 25-29.

20 The Health and Social Care Information Centre. Ethnic Category Code 2016. [Available from http://www.datadictionary.nhs.uk/data_dictionary/attributes/e/ end/ethnic_category_code_de.asp?shownav $=1]$.

21 Cole TJ, Lobstein T. Extended international (IOTF) body mass index cut-offs for thinness, overweight and obesity. Pediatr Obesity 2012; 7: 284-294. 
22 The Health and Social Care Information Centre. National Child Measurement Programme: England, 2010/11 school year. London: Department of Health [http:// content.digital.nhs.uk/catalogue/PUB03034]; 2011.

23 Zilanawala A, Davis-Kean P, Nazroo J, Sacker A, Simonton S, Kelly Y. Race/ethnic disparities in early childhood BMI, obesity and overweight in the United Kingdom and United States. Int J Obes 2015; 39: 520-529.

24 Massion S, Wickham S, Pearce A, Barr B, Law C, Taylor-Robinson D. Exploring the impact of early life factors on inequalities in risk of overweight in UK children: findings from the UK Millennium Cohort Study. Arch Dis Child 2016; 101: 724-730.

25 Lee S, Bountziouka V, Lum S, Stocks J, Bonner R, Naik M et al. Ethnic variability in body size, proportions and composition in children aged 5 to 11 years: is ethnicspecific calibration of bioelectrical impedance required? PLoS One 2014; 9: e113883.

26 Shaw NJ, Crabtree NJ, Kibirige MS, Fordham JN. Ethnic and gender differences in body fat in British schoolchildren as measured by DXA. Arch Dis Child 2007; 92 : 872-875.

27 El-Sayed AM, Scarborough P, Galea S. Ethnic inequalities in obesity among children and adults in the UK: a systematic review of the literature. Obesity Rev 2011; 12: e516-e534.

28 Corbin LJ, Richmond RC, Wade KH, Burgess S, Bowden J, Smith GD et al. BMI as a modifiable risk factor for type 2 diabetes: refining and understanding causal estimates using mendelian randomization. Diabetes 2016; 65: 3002-3007.

29 Whitlock G, Lewington S, Sherliker P, Clarke R, Emberson J, Halsey J et al. Body-mass index and cause-specific mortality in 900000 adults: collaborative analyses of 57 prospective studies. Lancet 2009; 373: 1083-1096.
30 Rush EC, Puniani K, Valencia ME, Davies PS, Plank LD. Estimation of body fatness from body mass index and bioelectrical impedance: comparison of New Zealand European, Maori and Pacific Island children. Eur J Clin Nutr 2003; 57: 1394-1401.

31 Carpenter CL, Yan E, Chen S, Hong K, Arechiga A, Kim WS et al. Body fat and bodymass index among a multiethnic sample of college-age men and women. J Obesity 2013; 2013: 790654.

32 Wells JC, Fewtrell MS. Measuring body composition. Arch Dis Child 2006; 91 : 612-617.

\section{cc) (i)}

This article is licensed under a Creative Commons Attribution 4.0 International License, which permits use, sharing, adaptation, distribution and reproduction in any medium or format, as long as you give appropriate credit to the original author(s) and the source, provide a link to the Creative Commons license, and indicate if changes were made. The images or other third party material in this article are included in the article's Creative Commons license, unless indicated otherwise in a credit line to the material. If material is not included in the article's Creative Commons license and your intended use is not permitted by statutory regulation or exceeds the permitted use, you will need to obtain permission directly from the copyright holder. To view a copy of this license, visit http://creativecommons. org/licenses/by/4.0/

(c) The Author(s) 2018

Supplementary Information accompanies this paper on International Journal of Obesity website (http://www.nature.com/ijo) 